\begin{tabular}{|c|l|}
\hline Title & Deuterium retention of low activation ferritic steel and boronized wall in JFT-2M \\
\hline Author(s) & Y amauchi, Y.; Y amaguchi, K.; Hirohata, Y.; Hashiba, M.; Hino, T.; T suzuki, K.; Kusama, Y. \\
\hline Citation & $\begin{array}{l}\text { Fusion Engineering and Design, 81(1-7), 315-319 } \\
\text { https://doi.org/10.1016/.fusengdes.2005.09.031 }\end{array}$ \\
\hline Issue Date & 2006 \\
\hline Doc URL & http://hdl.handle.net/2115/5925 \\
\hline Type & article (author version) \\
\hline File Information & FED81-1-7.pdf \\
\hline
\end{tabular}

Instructions for use 


\section{Deuterium retention of low activation ferritic steel and boronized wall in JFT-2M}

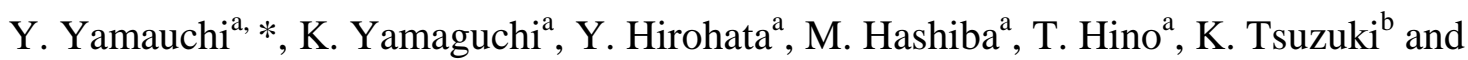
Y. Kusama ${ }^{\mathrm{b}}$

a Laboratory of Plasma Physics and Engineering, Hokkaido University, Kita-13, Nishi-8, Kita-ku, Sapporo, 060-8628 JAPAN

b Japan Atomic Energy Research Institute, Shirakata Shirane, Tokai-mura, Nakagun, Ibaraki, 319-1195, JAPAN

*Corresponding author : Y. Yamauchi

Phone \& Fax number : +81-11-706-7194

E-mail : yamauchi@qe.eng.hokudai.ac.jp

Postal address: Laboratory of Plasma Physics and Engineering, Hokkaido

University, Kita-13, Nishi-8, Kita-ku, Sapporo, 060-8628 JAPAN

Abstract

Deuterium retention and erosion of F82H exposed to JFT-2M plasmas and the effect of boronization on the deuterium retention were examined based on material probe analysis. The amount of retained deuterium almost saturated after 300 main discharges of deuterium. The retention of helium was clearly observed after helium 
glow discharge. The desorption temperature was approximately $600 \mathrm{~K}$. While no significant change in the surface atomic composition was observed after the exposure of main discharges, the mixture layer of carbon, iron and oxygen was observed after the helium glow discharge due to surface erosion and redeposition of eroded particles. After the boronization using trimethylboron, both carbon and boron deposited at the surface. The atomic ratio of $\mathrm{B}$ to $\mathrm{C}$ was $1 / 3$. The amount of retained deuterium significantly increased, three times larger than that before the boronization, owing to that a large amount of deuterium is trapped in the carbon content.

Keywords: JFT-2M, material probe, ferritic steel, deuterium retention, boronization 


\section{Introduction}

Low activation ferritic steel, F82H (8Cr-2W), is a leading candidate for structure material of a fusion demonstration reactor [1]. In JFT-2M tokamak, Advanced Material Tokamak Experiment (AMTEX) has been performed in order to test the compatability of the low activation ferritic steel with plasma and study the plasma-surface interaction related to the ferritc steel $[2,3]$. Boronization has been performed in order to reduce the impurity influx and to minimize the radiation loss power $[4,5]$ in addition to the helium discharge cleaning. It is important to investigate the plasma-surface interactions such as deuterium retention and erosion of the ferritic steel during main discharges and/or the helium glow discharge cleanings. The effect of boronization on the plasma surface interaction also has to be clarified.

In the present study, the deuterium retention and the erosion of F82H exposed to JFT-2M plasmas and the effect of boronization on the deuterium retention were examined based on material probe analysis.

\section{Experiment}

The F82H sample probes mechanically polished were placed on the sample station, which was located the radial position almost same as the ferritic steel plates (approcimately $3 \mathrm{~cm}$ behind the plates and $50 \mathrm{~mm}$ behind graphite guard limiters) in the JFT-2M tokamak, as shown in fig.1. Here, this photograph shows different port of actual position of the sample station. Four kinds of the F82H samples were prepared. Sample A was exposed to approximately 300 deuterium main discharges (Jun.-Jul., 2002). Sample A was also exposed to the helium glow discharge for $\sim 1$ h. Sample B was exposed to only helium glow discharges for 6 h. In the helium glow discharge, the 
discharge voltage was $320 \mathrm{~V}$, the helium pressure $0.3 \mathrm{~Pa}$, and the discharge current $2 \mathrm{~A}$. Sample C was exposed to approximately 350 deuterium main discharges (Jan.-Mar., 2003) after the boronization. Sample D was exposed to the helium gow discharges in addition to the main discharges after the boronization. The condition of the helium glow discharges after the boronization was similar to that before the boronization. The boronization was conducted using glow discharge with a mixture gas, $1 \% \mathrm{~B}\left(\mathrm{CH}_{3}\right)_{3}$ (trimethylboron) + He. In every case, the sample temperature was nearly room temperature. The deuterium retention of these samples after the plasma exposure was investigated by using thermal desorption spectroscopy, TDS. The details of the TDS apparatus were described before [6]. The sample was heated from room temperature to $1073 \mathrm{~K}$ with a ramp rate of $0.5 \mathrm{~K} / \mathrm{s}$. The desorption rate of deuterium was quantitatively measured using a quadropole mass spectrometer, QMS [7]. The retained amount of deuterium was obtained by integrating the desorption rates of gases containing $\mathrm{D}$ over the heating time. The depth profile of atomic composition was also examined by ex-situ Auger electron spectroscopy, AES, with argon ion etching, in order to investigate the erosion and the deposition due to the plasma irradiation.

\section{Results}

\subsection{Surface modification by erosion and deposition}

Figures 2 show depth profiles of atomic composition for Sample A, (a), Sample B, (b), Sample C, (c), and Sample D, (d). Before the plasma exposure, the F82H sample had the oxide layer with thichness of $\sim 10 \mathrm{~nm}$ and contamination of carbon at the top surface. After the exposure to the deuterium main discharge (fig.2(a)), no significant change in profile of atomic composition was observed, compared with that before the 
exposure. This result indicates that the erosion and redeposition hardly occurred at the region around the sample station during the main discharge. After the helium glow discharges (fig.2(b)), the mixture layer of carbon, iron and oxygen with the thickness of $10 \mathrm{~nm}$ was observed at the surface. The mixture layer might have been formed by the surface sputtering, and the depositions of carbon eroded at the divertor and the limiter made by graphite, and iron eroded at the ferrtic steel wall. The mixture layer at the surface owing to helium glow discharge has been observed in other fusion devices [8, 9]. After the boronization followed by the exposure to the deuterium main discharges (fig.2(c)), the boronized layer with a thickness of $\sim 40 \mathrm{~nm}$ was observed at the surface. The thickness of boronized layer was comparable with that before the exposure of the main discharges (50-60 nm). No significant erosion of the boronized layer was observed due to the exposure of the main discharges. The atomic ratio of boron to carbon, B/C, was approximately $1 / 3$, which was similar to that of the boron film prepared by helium discharge using trimethylboron in RFX [10]. After the boronization followed by the exposure to the deuterium main discharges and the helium glow discharges (fig.2(d)), the thickness of boronized layer after the exposure of the helium glow discharges was approximately $30 \mathrm{~nm}$, which was slightly thinner than that before the exposure. These results suggest that little erosion of boron film due to helium glow discharcharge occurs.

\subsection{Deuterium retention}

Figures 3 show thermal desorption spectra of gases containing deuterium atom and helium (He) desorbed from Sample A, (a), Sample B, (b), Sample C, (c), and Sample D, (d). The deuterium retained in the sample was desorbed in forms of $\mathrm{D}_{2}, \mathrm{HD}$, water and 
hydrocarbon during the TDS measurement. After the exposure to the deuterium main discharge (fig.3(a)), desorptions of $\mathrm{D}_{2}$ including with $\mathrm{He}(\mathrm{m} / \mathrm{e}=4)$ had two peaks around at $600 \mathrm{~K}$ and $900 \mathrm{~K}$. He desorption of the F82H sample exposed to only the helium glow discharges (fig.3(b)) had peaks around 600K. HD desorption behavior for Sample A and He desorption behavior for Sample B suggest that the peak of $\mathrm{m} / \mathrm{e}=4$ around at $600 \mathrm{~K}$ of Sample $\mathrm{A}$ is due to He desorption. In the signals of $\mathrm{m} / \mathrm{e}=20$ and 19 , the contribution of hydrocarbon such as $\mathrm{CD}_{4}$ is included. However, the behavior of these signals was very similar to that of $\mathrm{H}_{2} \mathrm{O}$, so that the contribution of hydrocarbon in these signals may be small.

After the boronization followed by the exposure to the deuterium main discharges (fig.3(c)), the large desorptions of $\mathrm{HD}$ and $\mathrm{D}_{2}$ above $800 \mathrm{~K}$ were observed, compared to the case before the boronization (fig. 3 (a)). The thermal desorption behavior of the signal of $\mathrm{m} / \mathrm{e}=20$ and 19 was very similar to that of $\mathrm{CH}_{4}$. The contribution of hydrocarbon such as $\mathrm{CD}_{4}$ to these signal might have been large, compared with the case of the before the boronization. After the boronization followed by the exposure to the deuterium main discharges and the helium glow discharges (fig.3(d)), the desorptions at the low temperature region $(\sim 700 \mathrm{~K})$ decreased and the desorptions at the high temperature region increased, compared with the case without the helium glow discharges (fig.3(c)).

Figure 4 shows the amounts of retained deuterium in the F82H samples. The amount of retained deuterium in the sample exposed to the main discharges was comparable with that exposed to the deuterium ions $(1.7 \mathrm{keV})$ with high fluence in the ion irradiation apparatus [11]. This result indicates that the amount of retained deuterium in the sample exposed to main discharges almost saturated. The amount of 
retained deuterium after the boronization was approximately three times larger than that before the boronization. This is owing to that the deuterium is well trapped in both carbon [11, 12] and boron [13], compared with the steel. The amount of retained deuterium after the boronization followed by the deuterium main discharge and the helium glow discharges was almost similar to that before the glow discharges. This is owing to that the deuterium in carbon is hardly removed [12].

\section{Conclusion}

Deuterium retention and erosion of $\mathrm{F} 82 \mathrm{H}$ exposed to deuterium main discharge and/or helium glow discharge in JFT-2M and the effect of boronization on the deuterium retention were investigated based on material probe analysis. While no significant change in the depth profile of atomic composition was observed after the exposure of deuterium main discharges, the mixture layer of carbon, iron and oxygen was observed after the helium glow discharges due to the surface erosion and redeposition of eroded particles. The boronized layer (thickness: $\sim 40 \mathrm{~nm}$ ) with a large content of carbon was formed by the boronization. Signifinant change in atomic composition of the boronized layer was not observed by the exposure of the deuterium main discharges. The deuterium retained in the sample was desorbed in forms of $\mathrm{D}_{2}$, HD, water and hydrocarbon during the TDS measurement. Amount of desorbed hydrocarbon increased after the boronization. The amount of retained deuterium after the boronization was approximately three times larger than that before the boronization, owing to a large amount retained in carbon. The amount of retained deuterium after the boronization followed by the deuterium main discharges and the helium glow discharges was almost similar to that before the glow discharges. 


\section{Acknowledgement}

This work was supported by Grand-in-Aid for Scientific Research (KAKENHI 15760619).

Reference

[1] K. Shiba, A. Hishinuma at al, Properties of Low Activation Ferritic Steel F82H IEA Heat, JAERI-Tech 97-038 (1997). (in Japanese)

[2] H. Kimura, M. Sato et al, Progress of advanced material tokamak experiment (AMTEX) program on JFT-2M, Fusion Eng. and Design 56-57 (2001) 837-841.

[3] K. Tsuzuki, M. Sato et al, Recent activities on the compatibility of the ferritic steel wall with the plasma in the JFT-2M tokamak, J. Nucl. Mater. 307-311 (2002) 13861390.

[4] H. Kawashima, S. Sengoku et al, Characteristics of boundary plasmas after the removal of divertor baffle plates and boronization on JFT-2M, J. Nucl. Mater. 313316 (2003) 1338-1342.

[5] H. Ninomiya, A. Kitsunezaki et al, Research activities on Tokamaks in Japan: JT60U, JFT-2M, and TRIAM-1M, Fusion Sci. and Technol. 42 (2002) 7-31.

[6] Y. Yamauchi, Y. Hirohata et al, Deuterium retention of DIII-D DiMES sample, J. Nucl. Mater. 266-269 (1999) 1257-1260.

[7] Y. Nakayama, S. Fukuda and T. Yamashina, Quantitative mass spectrometric analysis of mixed gases released from various materials, J. Vac. Soc. Jpn. 32 (1989) 415-418. (in Japanese)

[8] T. Hino, A. Sagara et al, Material probe analysis for plasma facing surface in the large helical device, Nucl. Fusion 44 (2004) 496-502. 
[9] H. Amemiya, S. Ishii et al, Study of metal deposition on low Z samples during ECR and glow discharge cleaning in TEXTOR, J. Nucl. Mater. 145/147 (1987) 647-650.

[10]P. Sonato, V. Antoni et al, Boronization with trimethylboron in the reversed field pinch RFX, J. Nucl. Mater. 227 (1996) 259-265.

[11]K. Yamaguchi, Y. Yamauchi et al, Deuterium retention of low activation ferritic steel F82H, J. Vac. Soc. Jpn 46 (2003) 449-452.

[12]Y. Yamauchi, Y. Hirohata et al, Hydrogen retention of $\mathrm{B}_{4} \mathrm{C}$ converted graphite, J. Nucl. Mater. 220-222 (1995) 851-855.

[13]K. Tsuzuki, M. Natsir et al, Hydrogen absorption behavior into boron films by glow discharges in hydrogen and helium, J. Nucl. Mater. 241-243 (1997) 1055-1059. 
Figure Captions

Figure 1 Poloidal location of sample station. Actually, sample station was located at different port from this port.

Figure 2 Depth profiles of atomic composition for F82H sample.

(a) After exposure to deuterium main discharges

(b) After exposure to helium glow discharges

(c) After boronization followed by exposure to deuterium main discharges

(d) After boronization followed by exposure to deuterium main discharges and helium glow discharge

Figure 3 Thermal desorption spectra of gases containing deuterium atom and helium desorbed from the F82H samples.

(a) After exposure to deuterium main discharges

(b) After exposure to helium glow discharges

(c) After boronization followed by exposure to deuterium main discharges

(d) After boronization followed by exposure to deuterium main discharges and helium glow discharge

Figure 4 Amounts of retained deuterium for the F82H samples after plasma exposures. 


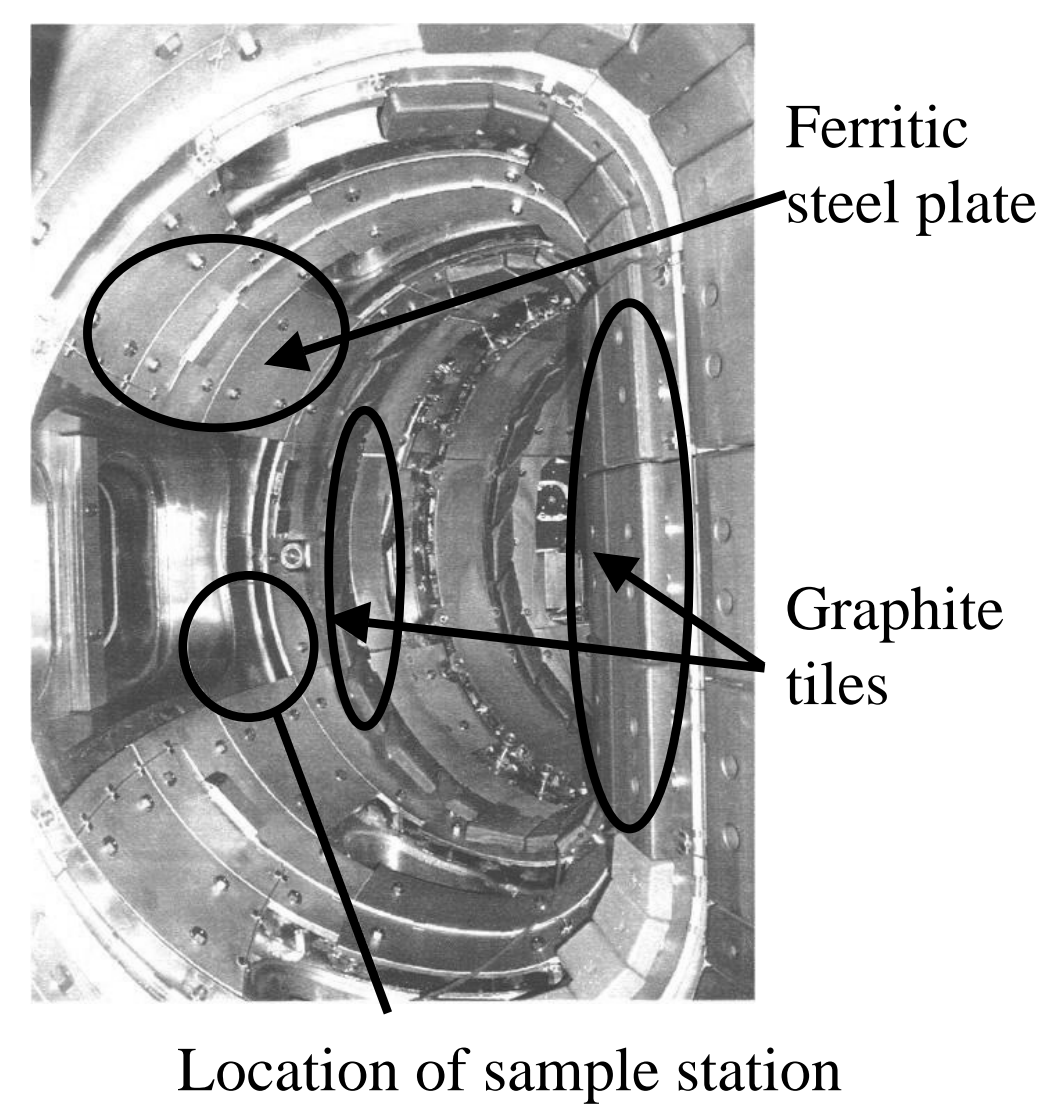

Fig.1 Y. Yamauchi 
(a)

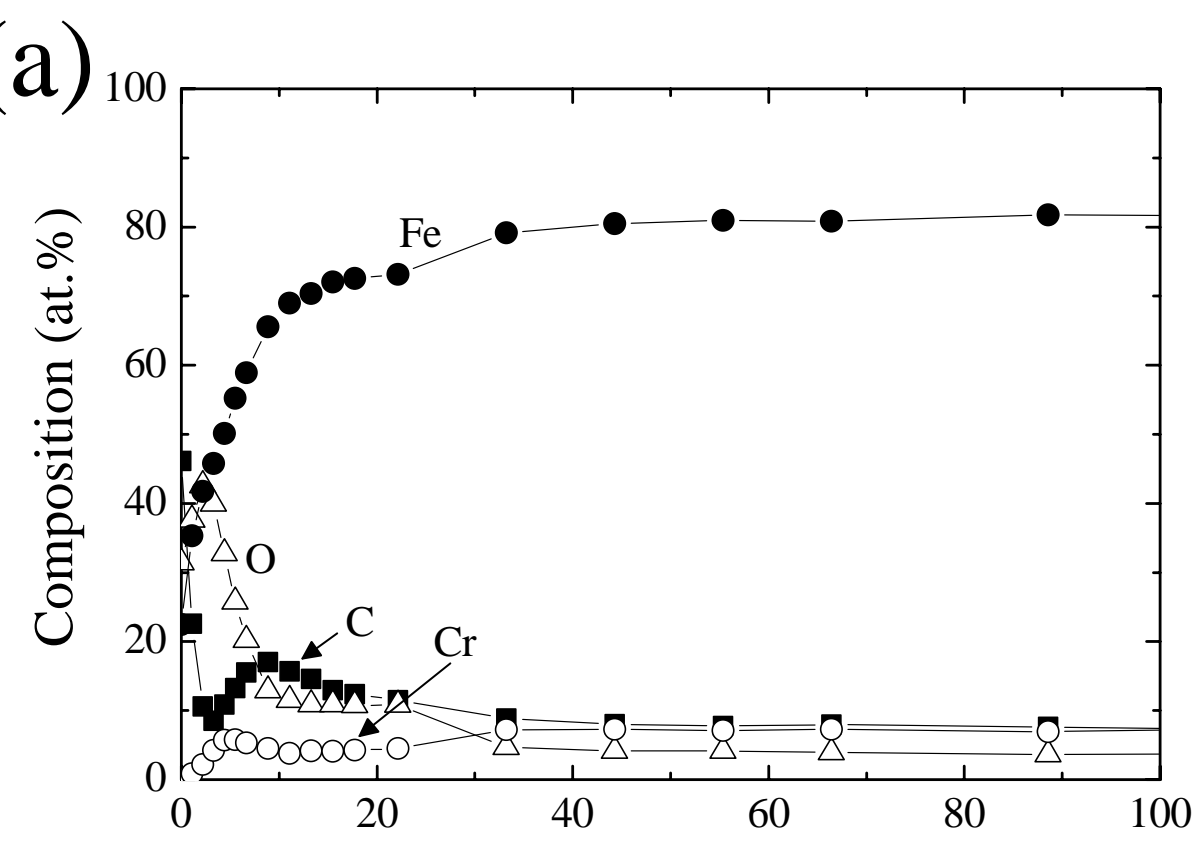

(c)

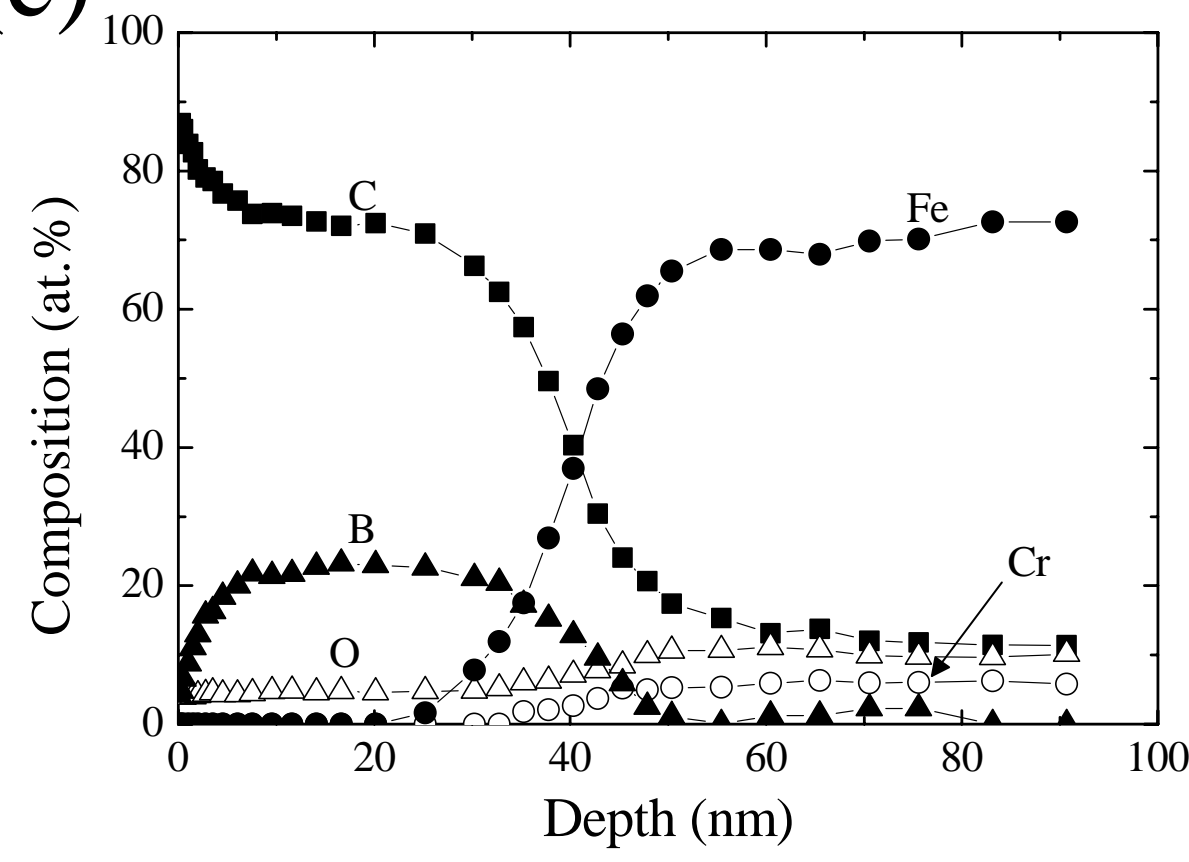

(b)

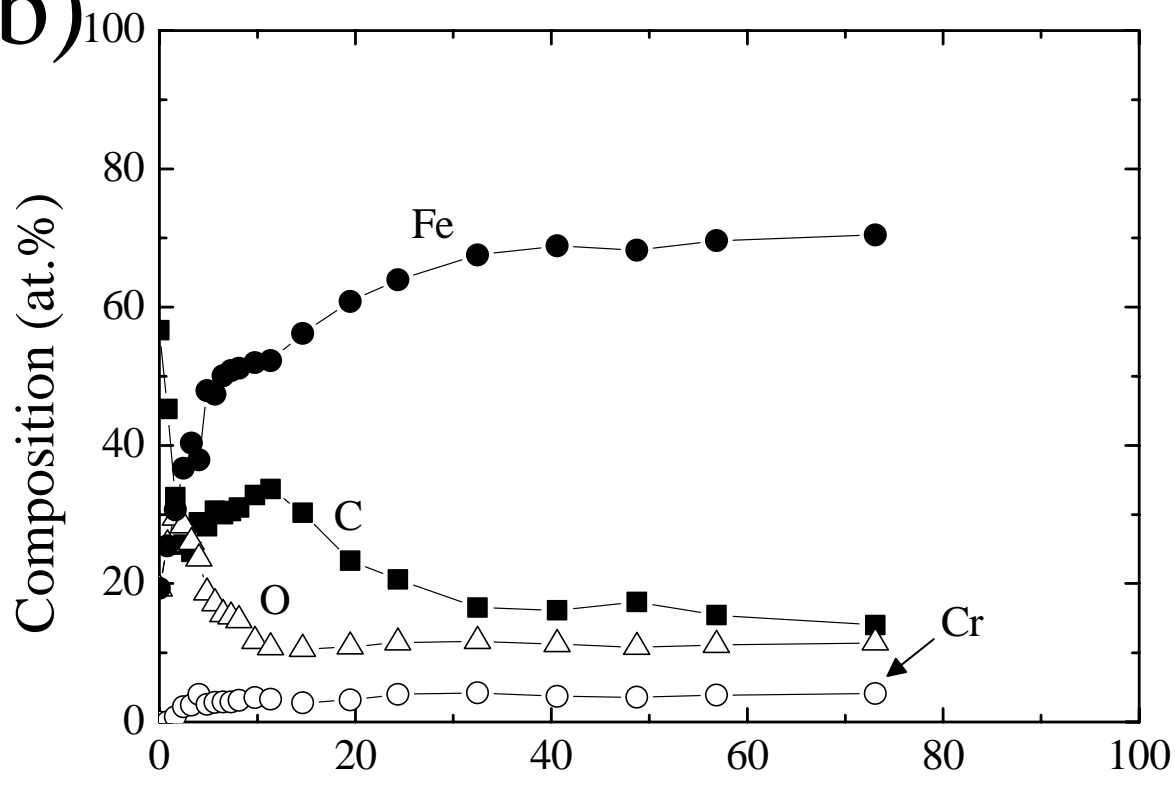

(d)

Depth (nm)

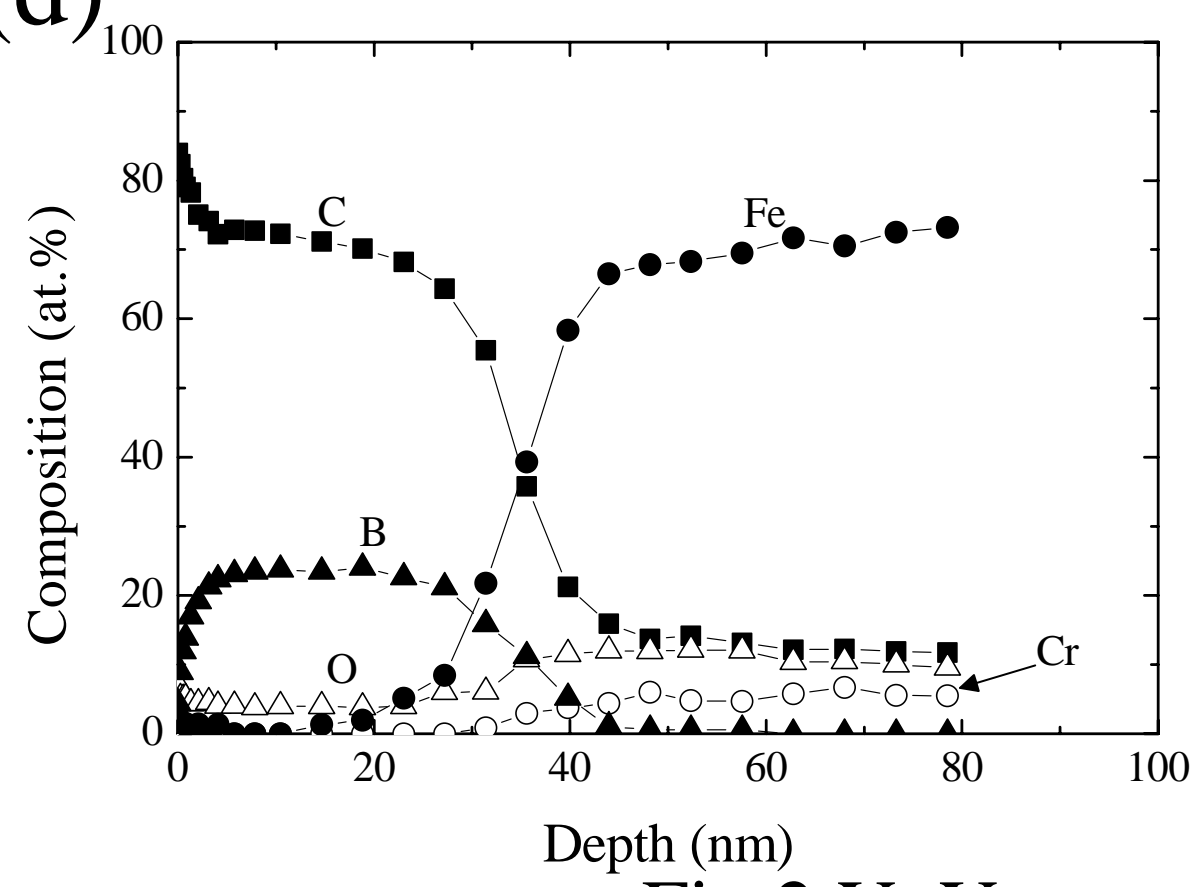

Fig.2 Y. Yamauchi 
(a)

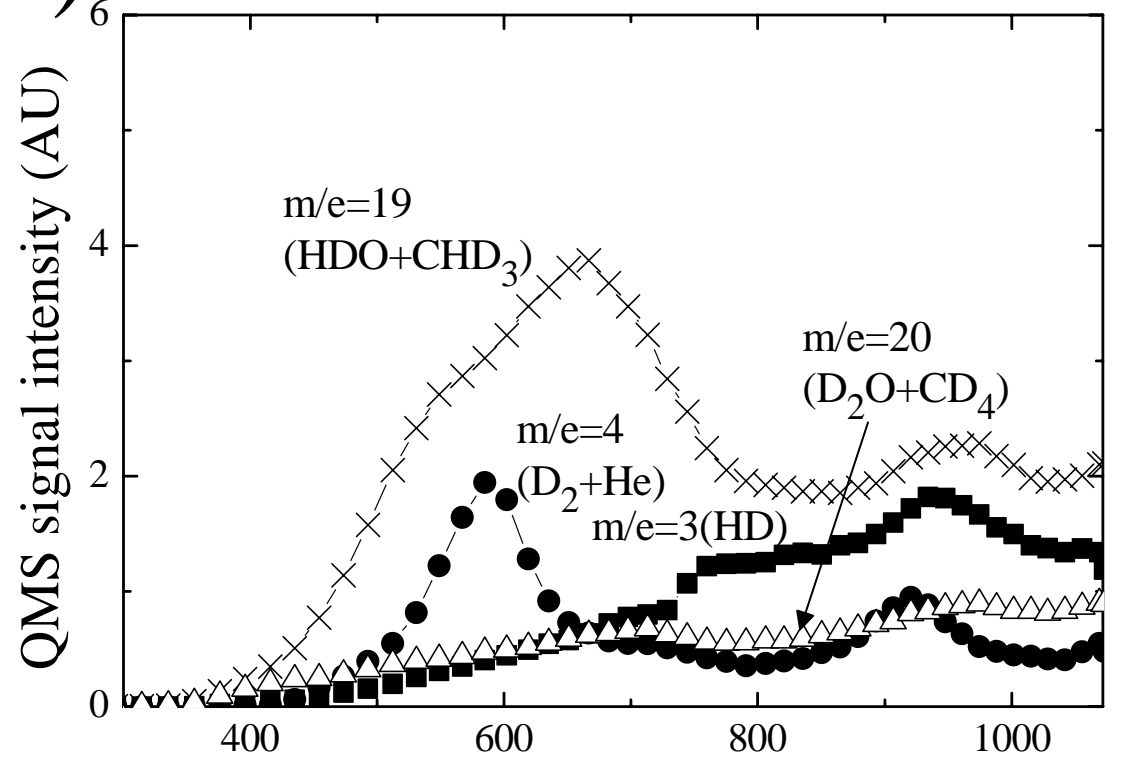

(c)

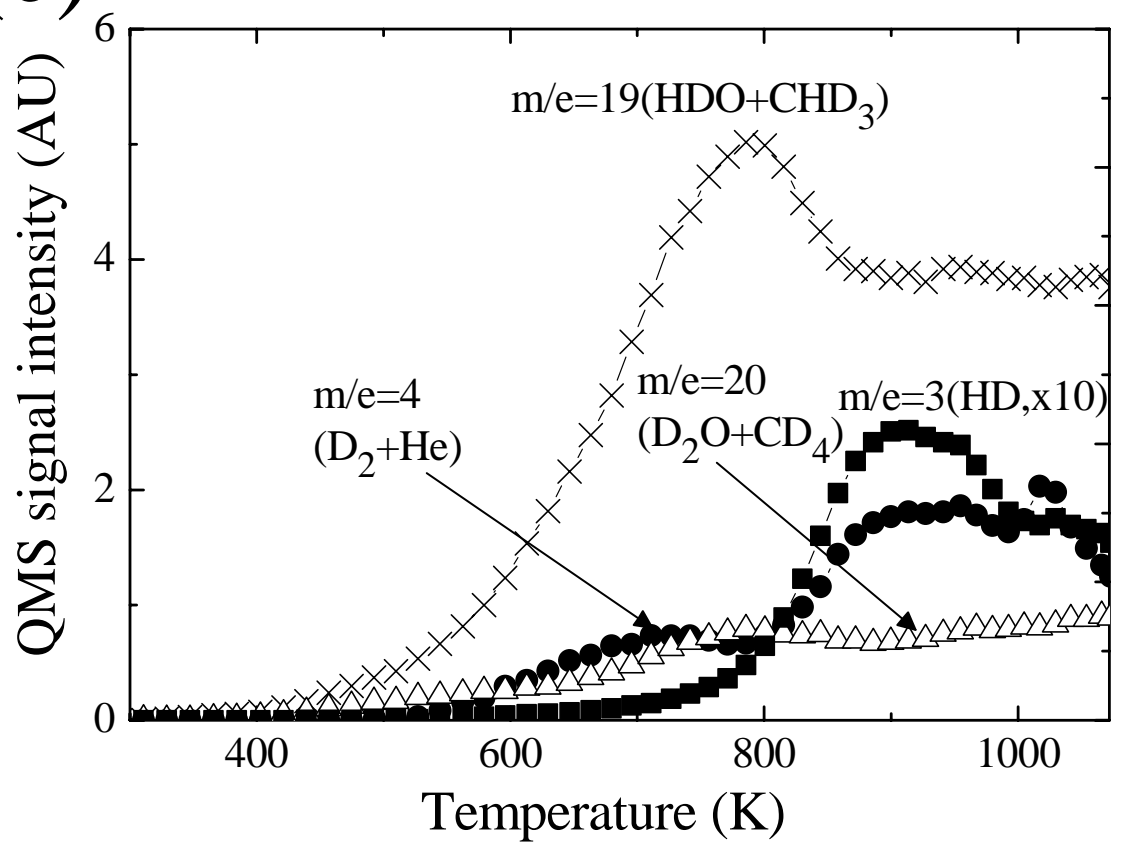

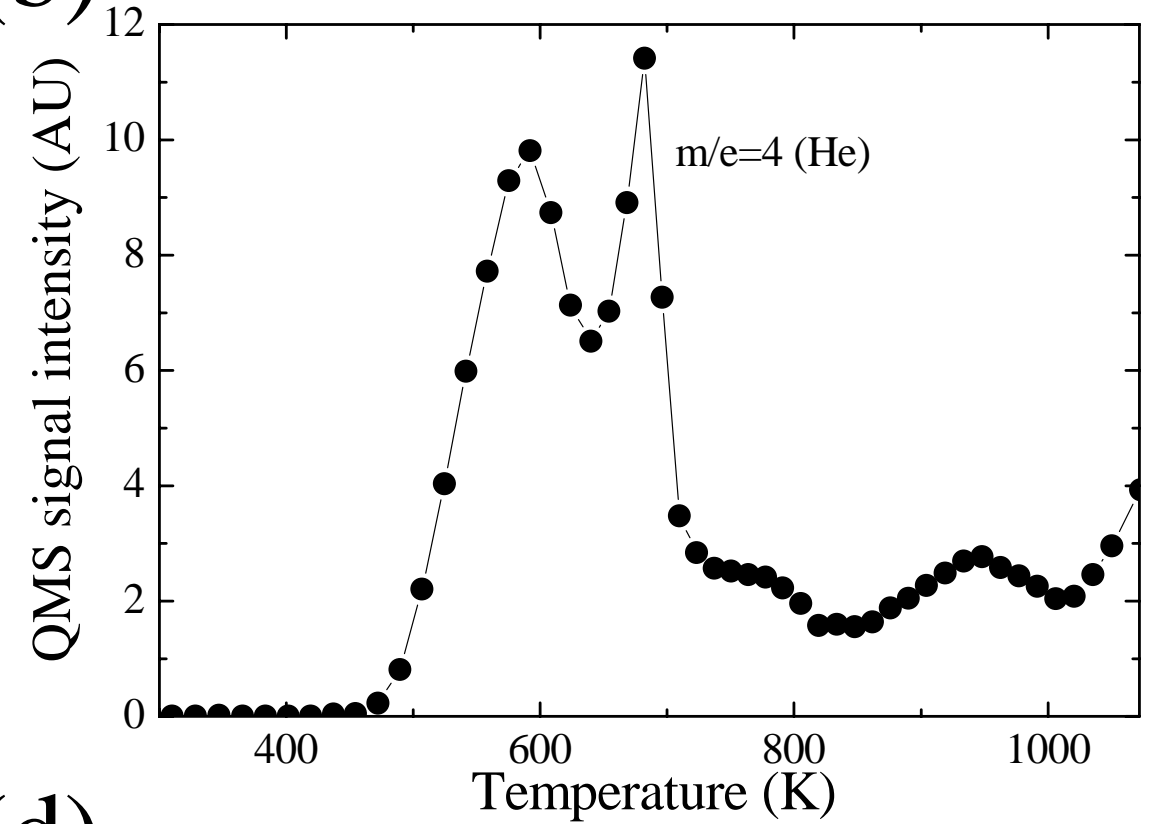

(d)

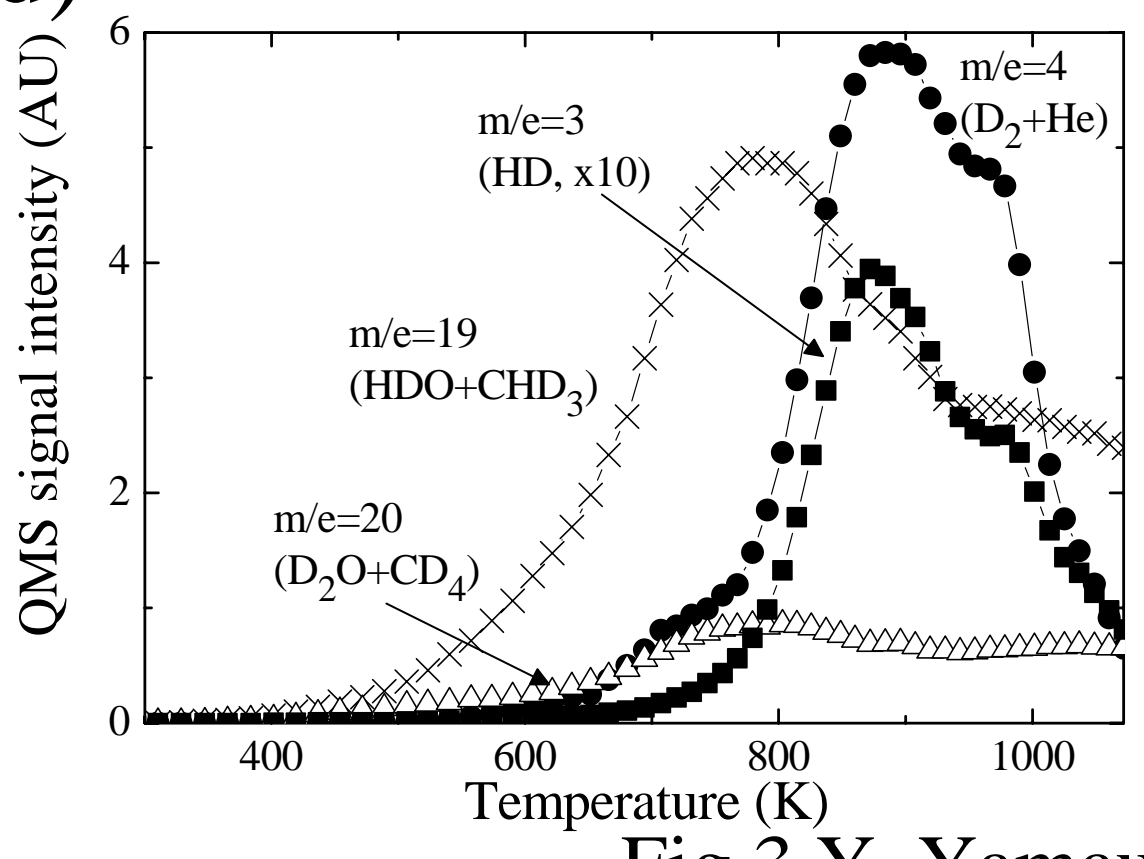

Fig.3 Y. Yamauchi 


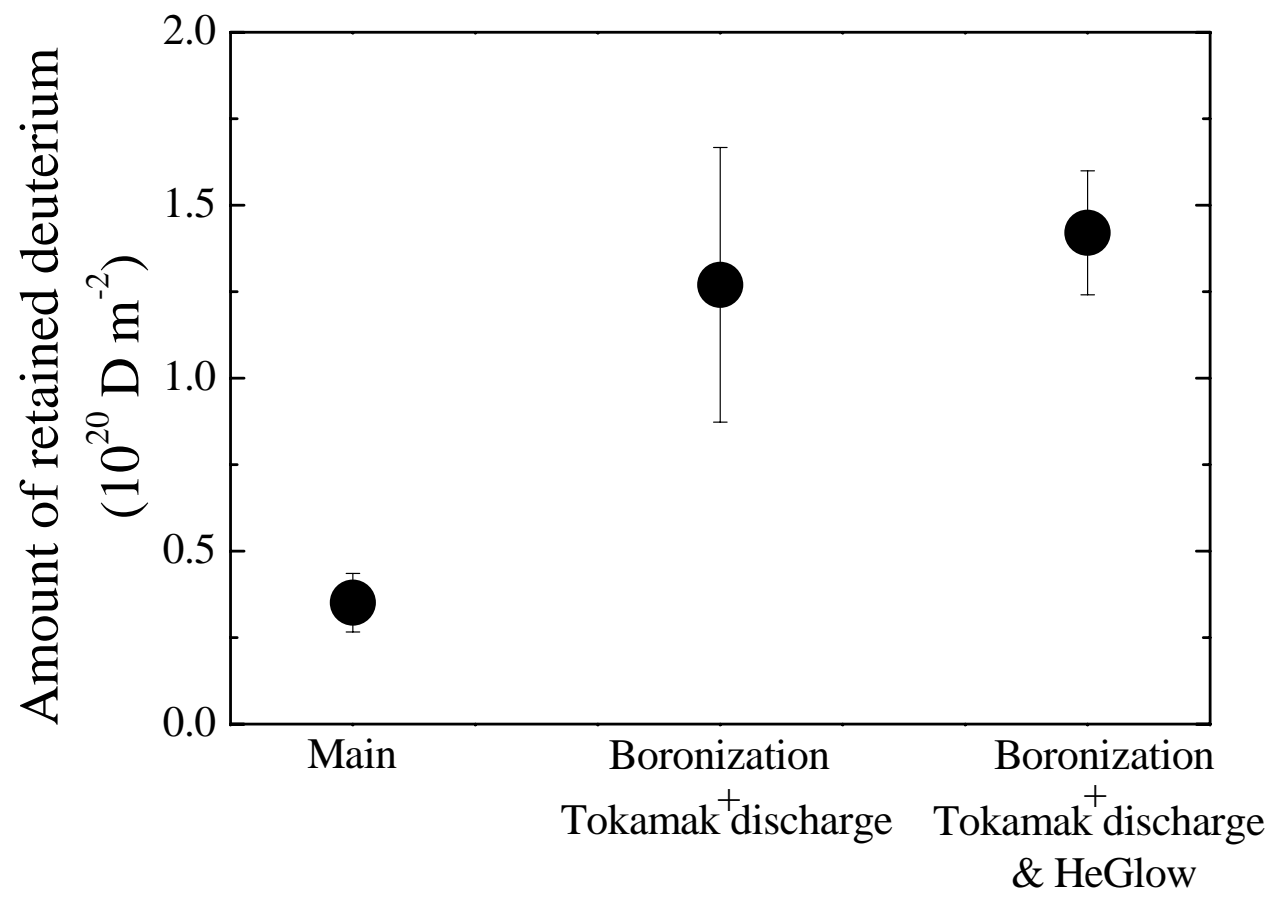

Fig.4 Y. Yamauchi 